\title{
Vitamin D is associated with blood lead exposure through bone turnover in type 2 diabetes patients
}

\author{
Haojie Zhang ${ }^{1, *}$, Yuke Cui ${ }^{1, *}$, Ruihua Dong ${ }^{2, *}$, Wen Zhang ${ }^{1}$, Shihan Chen ${ }^{1}$, Heng Wan ${ }^{1}$, Chi Chen ${ }^{1}$, Yi Chen ${ }^{1}$, \\ Yuying Wang ${ }^{1}$, Chunfang Zhu' ${ }^{1}$, Bo Chen ${ }^{2}$, Ningjian Wang ${ }^{1}$ and Yingli Lu' \\ ${ }^{1}$ Institute and Department of Endocrinology and Metabolism, Shanghai Ninth People's Hospital, Shanghai JiaoTong University School of Medicine, \\ Shanghai, China \\ ${ }^{2}$ Key Laboratory of Public Health Safety of Ministry of Education, Collaborative Innovation Center of Social Risks Governance in Health, School of Public \\ Health, Fudan University, Shanghai, China \\ Correspondence should be addressed to B Chen or N Wang or Y Lu: chenb@fudan.edu.cn or wnj486@126.com or luyingli2008@126.com \\ *(H Zhang, Y Cui and R Dong contributed equally to this work)
}

\begin{abstract}
Background: Bone is thought to be the reservoir of the human lead burden, and vitamin $\mathrm{D}$ is associated with bone turnover. We aimed to explore whether exposure to lower 25-hydroxy vitamin D (25(OH)D) levels was associated with higher blood lead levels (BLLs) by increasing the bone turnover rate in individuals with type 2 diabetes. Methods: A total of 4103 type 2 diabetic men and postmenopausal women in Shanghai, China, were enrolled in 2018. Their 25(OH)D, $\beta$-C-terminal telopeptide ( $\beta$-CTX), N-MID osteocalcin and procollagen type $1 \mathrm{~N}$-peptide (P1NP) levels were detected. Their BLLs were determined by atomic absorption spectrometry. Mediation analyses were performed to identify the possible role that bone turnover played in the underlying mechanisms.

Results: In both the men and postmenopausal women, all three bone turnover markers were inversely associated with $25(\mathrm{OH}) \mathrm{D}$ and positively associated with the BLL (all $P<0.01$ ) after adjusting for age, current smoking habits, metabolic parameters, duration of diabetes, vitamin D intake, and use of anti-osteoporosis medication. In the mediation analyses, none of the direct associations between 25(OH)D and BLL was significant for the three bone turnover markers, but all three bone turnover markers were found to be significant mediators of the indirect associations between 25(OH)D and BLL. Conclusion: The association between vitamin D and BLL was fully mediated by bone turnover markers in type 2 diabetic patients (mediation effect). This finding suggested that vitamin D may protect against blood lead exposure from the bone reservoir by decreasing bone turnover in individuals with type 2 diabetes.
\end{abstract}

\section{Key Words}

- vitamin D

- bone turnover

- blood lead level

- type 2 diabetes

- mediation
Endocrine Connections (2021) 10, 378-386

\section{Introduction}

Type 2 diabetes mellitus is becoming a major public health concern, especially in China. Its estimated prevalence is up to $11 \%$, and approximately 109.6 million adults in China have diabetes (1). Research indicates that environmental and nutritional factors have been found to be associated with diabetes mellitus. Several studies have directly suggested that blood lead levels (BLLs) were higher in diabetic people than in non-diabetic people $(2,3)$. In addition, diabetic patients tend to have lower levels of vitamin $\mathrm{D}$ and higher rates of vitamin D deficiency $(4,5)$.

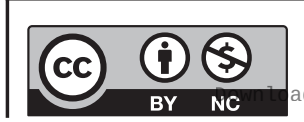


Lead, which was previously considered an environmental neurotoxin (6), is now also known to be an endocrine disruption factor that may induce metabolic and endocrine changes $(7,8)$. Over the past several decades, successful efforts have been made to reduce sources of lead exposure, and BLLs in Chinese children have gradually decreased over the past 10 years (9). However, BLLs remain relatively higher among the general population in China than in America $(10,11)$. In China, the sources of lead exposure are paint, industrial emissions, e-waste, and traditional medicines (12). Furthermore, over $90 \%$ of the total body burden of lead is retained in the skeleton in adults (13); thus, previously accumulated bone lead stores, with their half-lives of over 10 years, may be a source of blood lead (14). Considering the association between BLL and bone metabolism (15), bone may provide an endogenous source of exposure under conditions of increased bone turnover.

Vitamin D could regulate mineral and bone homeostasis and play a key role in providing adequate minerals for normal bone formation. Vitamin D deficiency causes secondary hyperparathyroidism and high bone turnover and results in bone loss (16). Notably, in older persons, bone markers showed a steep decrease when the serum 25-hydroxy vitamin D (25(OH)D) was increased up to approximately $40 \mathrm{nmol} / \mathrm{L}$, followed by a plateau (17). In light of an inverse correlation between vitamin $\mathrm{D}$ and BLL in previous studies (15), we hypothesized that lower levels of vitamin D may raise BLLs by enhancing bone turnover in the elderly.

Therefore, using data from a population-based METAL study (Environmental Pollutant Exposure and Metabolic Diseases in Shanghai, www.chictr.org.cn, ChiCTR1800017573), we analyzed the associations among 25(OH)D, BLLs and bone formation and resorption markers in type 2 diabetic men and postmenopausal women and investigated whether bone turnover markers mediated the association between 25(OH)D and BLL.

\section{Methods}

\section{Study population}

The cross-sectional METAL study was conducted from April to June 2018. Participants were randomly enrolled from seven communities in Huangpu and Pudong districts, Shanghai, China. More detailed sampling information was published in previous articles (18). A total of 4937 subjects with diabetes who were 23-99 years old underwent examination. We excluded participants who were missing complete laboratory results $(n=8)$ or questionnaire data $(n=116)$ and did not have BLL, $25(\mathrm{OH}) \mathrm{D}$ or bone turnover marker results $(n=619)$. Then, we excluded 91 premenopausal women. Ultimately, 1936 men and 2167 postmenopausal women were included (Supplementary Fig. 1, see section on supplementary materials given at the end of this article).

The study protocol was approved by the Ethics Committee of Shanghai Ninth People's Hospital of the Shanghai Jiao Tong University School of Medicine (2017(210)). The study protocol conformed to the ethical guidelines of the 1975 Declaration of Helsinki as reflected by the a priori approval by the appropriate institutional review committee (19). Informed consent was obtained from all participants included in the study.

\section{Measurements}

A questionnaire about sociodemographic characteristics, medical history, family history, and lifestyle factors was adopted during the interview. The same group of trained and experienced personnel in the SPECT-China study (20, $21)$ conducted the interviews and clinical examinations, which included participant weight, height and blood pressure according to a standard protocol. The BMI was calculated as the weight in kilograms divided by the height in meters squared. Current smoking was defined as having smoked at least 100 cigarettes in one's lifetime and currently smoking cigarettes (22).

Blood samples were obtained between 06:00 $\mathrm{h}$ and 09:00 $\mathrm{h}$ after the participants had fasted for at least $8 \mathrm{~h}$. The blood was refrigerated immediately after being collected, centrifuged for $2 \mathrm{~h}$, and the serum was aliquoted and frozen in a central laboratory. The BLL was determined by atomic absorption spectrometry (BH2200, China) (10). The 25(OH)D was detected using a chemiluminescence assay (ADVIA Centaur XP, Siemens). Glycated hemoglobin (HbA1c) was measured by HPLC (MQ-2000PT, Medconn, Shanghai, China). Fasting plasma glucose and lipid profiles were determined with a Beckman Coulter AU 680 (Brea, USA). Fasting plasma glucose, alanine aminotransferase (ALT), aspartate aminotransferase (AST) and lipid profiles were determined with a Beckman Coulter AU 680 (Brea, USA). $\beta$-C-terminal telopeptide ( $\beta$-CTX), N-MID osteocalcin and procollagen type $1 \mathrm{~N}$-peptide (P1NP) were detected by chemiluminescence method (Roche E602). The inter-assay coefficients of variation were as follows: $3.30 \%$ (P1NP), 1.81\% (N-MID osteocalcin) and $7.60 \%$ $(\beta$-CTX). The intra-assay coefficients of variation were as

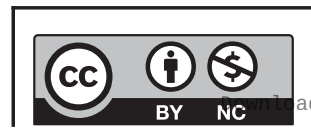

This work is licensed under a Creative Commons Attribution-NonCommercial 4.0 International License. ded from Bioscientifica.com at 04/26/2023 11:27:40AM 
follows: $3.0 \%(\mathrm{P} 1 \mathrm{NP}), 0.80 \%$ (N-MID osteocalcin) and $5.50 \%(\beta-\mathrm{CTX})$.

\section{Definition}

Vitamin D deficiency was defined as $25(\mathrm{OH}) \mathrm{D} \leq 50$ $\mathrm{nmol} / \mathrm{L} 50 \mathrm{nmol} / \mathrm{L}$ (23). Hypertension was assessed by systolic blood pressure $\geq 140 \mathrm{mmHg}$, diastolic blood pressure $\geq 90 \mathrm{mmHg}$, or a self-reported previous diagnosis of hypertension by physicians (24). Dyslipidemia was defined as total cholesterol $\geq 6.22 \mathrm{mmol} / \mathrm{L}(240 \mathrm{mg} / \mathrm{dL})$, triglycerides $\geq 2.26 \mathrm{mmol} / \mathrm{L}(200 \mathrm{mg} / \mathrm{dL})$, LDL-C $\geq 4.14$ $\mathrm{mmol} / \mathrm{L}(160 \mathrm{mg} / \mathrm{dL}), \mathrm{HDL}-\mathrm{C}<1.04 \mathrm{mmol} / \mathrm{L}(40 \mathrm{mg} / \mathrm{dL})$, or a self-reported previous diagnosis of hyperlipidemia by physicians, according to the modified National Cholesterol Education Program-Adult Treatment Panel III (25). The estimated glomerular filtration rate (eGFR) was calculated according to the Chronic Kidney Disease Epidemiology Collaboration (CKD-EPI) equation for 'Asian origin' (26).

\section{Statistical analysis}

Data analyses were performed using IBM SPSS Statistics, Version 22 (IBM Corporation). A $P$-value $<0.05$ indicated significance (two-sided). The continuous variables were summarized as the mean (s.D.) or median (interquartile range), and categorical variables were summarized as percentages (\%).

We applied multiple linear regression models to analyze the association among the blood lead level, 25(OH)D, bone turnover markers and metabolic factors in men and postmenopausal women. The model was adjusted for age, current smoking habits, BMI, dyslipidemia, vitamin D intake, hypertension, duration of diabetes and use of anti-osteoporosis medication. The 25(OH)D and blood lead level were independent variables, and bone turnover markers and metabolic factors were dependent variables. The $25(\mathrm{OH}) \mathrm{D}$, blood lead level, P1NP, N-MID osteocalcin, $\beta$-CTX and triglycerides were natural logarithm-transformed. The association between vitamin D deficiency and metabolic factors was also assessed.

Then, we tested the mediation and moderation effects using the SPSS PROCESS macro with 5000 bootstrap samples (27). The mediation and moderation models were also adjusted for patient age, current smoking habits, BMI, vitamin D intake, dyslipidemia, hypertension, duration of diabetes and use of anti-osteoporosis medication if necessary. First, mediation analysis was used to clarify whether exposure $\mathrm{X}$ is proposed as influencing outcome
$\mathrm{Y}$ via intervening variable $\mathrm{M}$ (Fig. 1). In this study, we predicted that 'vitamin $\mathrm{D}^{\prime}$ impacts 'BLL', with bone metabolism represented by 'bone turnover markers' as mediator variables. PROCESS was operated using one independent variable $(25(\mathrm{OH}) \mathrm{D})$, mediators (P1NP, N-MID osteocalcin or $\beta$-CTX), and one dependent variable (BLL).

In the sensitivity analyses, to exclude the effect of the occupation of the study participants on exposure to environmental lead, we measured the association in participants who had been retired from their jobs for over 5 years (women over 60 and men over 65).

\section{Results}

\section{Characteristics of the diabetic participants}

For this study, we recruited 4103 type 2 diabetic participants consisting of 1936 men and 2167 postmenopausal women. The mean age was 67 years old (s.D. 8.8) in men and 67.4 (s.D. 7.7) in women who had experienced similar numbers of years of diabetes duration. The mean 25(OH)D was $44.3 \mathrm{nmol} / \mathrm{L} 3 \mathrm{nmol} / \mathrm{L}$ (s.D. 14.3) in men and 40.4 (s.D.) in women. The prevalence of vitamin D deficiency was $70.0 \%$ in men and $80.1 \%$ in postmenopausal women. The medians of BLL, P1NP, N-MID and $\beta$-CTX were $26 \mu \mathrm{g} / \mathrm{L}$ (IQR 18, 37), $34.8 \mathrm{ng} / \mathrm{mL}$ (IQR 27.4, 44.1), $9.3 \mathrm{ng} / \mathrm{mL}$ (IQR 7.4,11.7) and $0.17 \mathrm{ng} / \mathrm{mL}$ (IQR 0.12, 0.22) in men and $25 \mu \mathrm{g} / \mathrm{L}$ (IQR 18, 35), $44.5 \mathrm{ng} / \mathrm{mL}$ (IQR 34.7, 57.9), $12.2 \mathrm{ng} / \mathrm{mL}$ (IQR 9.6, 15.4) and $0.21 \mathrm{ng} / \mathrm{mL}$ (IQR 0.15, 0.28) in postmenopausal women. Postmenopausal women had significantly higher bone turnover markers

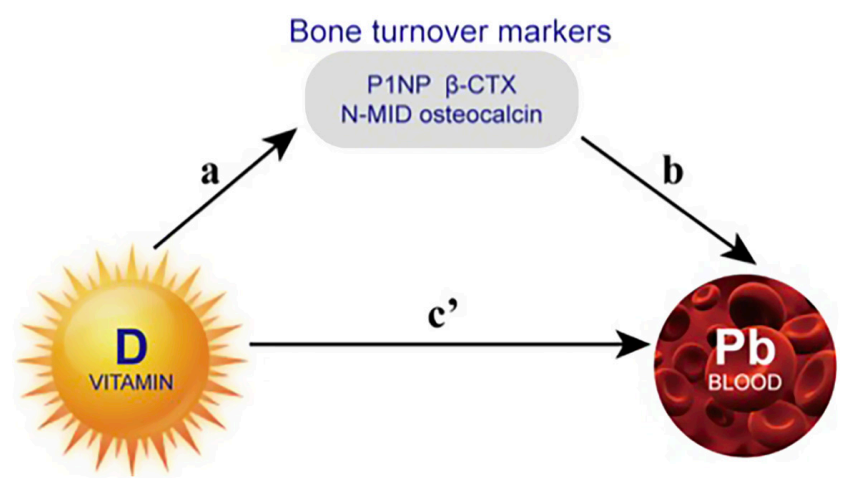

\section{Figure 1}

The conceptual mediation model. ' $a$ ' indicates the path from vitamin D (exposure) to bone turnover markers, 'b' indicates the path from bone turnover markers to blood lead level (outcome), and ' $c$ ' indicates the direct path from vitamin $D$ (exposure) to blood lead level when controlled for bone turnover markers. CTX, collagen type 1 C-telopeptide; P1NP, procollagen type $1 \mathrm{~N}$-terminal propeptide.

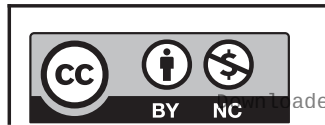

This work is licensed under a Creative Commons Attribution-NonCommercial 4.0 International License. ded from Bioscientifica.com at 04/26/2023 11:27:40AM via free access 
than old men. The prevalence of current smoking habits, hypertension, and dyslipidemia was 36.7, 78.0 and $63.2 \%$ in men and 2.4, 79.2 and $60.8 \%$ in women, respectively (Table 1).

\section{Associations among blood lead level, vitamin D, bone turnover markers and metabolic factors}

As shown in Fig. 2, in both men and postmenopausal women, both $25(\mathrm{OH}) \mathrm{D}$ and BLL showed significant decreasing and increasing trends, respectively, with increasing P1NP, N-MID osteocalcin and $\beta$-CTX levels (all $P<0.001)$.

Furthermore, in the linear regression analyses, we used the 25(OH)D and blood lead level as independent variables and bone turnover markers and metabolic factors as dependent variables. In both men and women, the P1NP, N-MID osteocalcin and $\beta$-CTX levels were inversely

Table 1 Characteristics of the study participants.

\begin{tabular}{|c|c|c|}
\hline & Men & $\begin{array}{c}\text { Postmenopausal } \\
\text { women }\end{array}$ \\
\hline$N$ & 1936 & 2167 \\
\hline Age, years & $67.0(8.8)$ & $67.4(7.7)$ \\
\hline $\begin{array}{l}\text { Duration of diabetes, } \\
\text { years }\end{array}$ & $9(3-15)$ & $9(3-15)$ \\
\hline $25(\mathrm{OH}) \mathrm{D}, \mathrm{nmol} / \mathrm{L}$ & $44.3(14.3)$ & $40.4(13.3)$ \\
\hline Vitamin D deficiency, \% & $70.0 \%$ & 80.1 \\
\hline Blood lead level, $\mu \mathrm{g} / \mathrm{L}$ & $26(18-37)$ & $25(18-35)$ \\
\hline $\mathrm{P} 1 \mathrm{NP}, \mathrm{ng} / \mathrm{mL}$ & $34.8(27.4-44.1)$ & 44.5 (34.7-57.9) \\
\hline $\begin{array}{l}\text { N-MID osteocalcin, } \\
\mathrm{ng} / \mathrm{mL}\end{array}$ & $9.3(7.4-11.7)$ & $12.2(9.6-15.4)$ \\
\hline$\beta-\mathrm{CTX}, \mathrm{ng} / \mathrm{mL}$ & $0.17(0.12-0.22)$ & $0.21(0.15-0.28)$ \\
\hline $\mathrm{BMI}, \mathrm{kg} / \mathrm{m}^{2}$ & $25.0(3.3)$ & $24.8(3.8)$ \\
\hline $\mathrm{FPG}, \mathrm{mmol} / \mathrm{L}$ & $7.8(2.4)$ & $7.8(2.5)$ \\
\hline $\mathrm{HbA} 1 \mathrm{c}, \%$ & $7.6(1.4)$ & $7.4(1.3)$ \\
\hline $\begin{array}{l}\text { eGFR, } \mathrm{mL} / \mathrm{min} \\
\text { per } 1.73 \mathrm{~m}^{2}\end{array}$ & $90.9(17.3)$ & $92.2(16.3)$ \\
\hline $\begin{array}{l}\text { Total cholesterol, } \\
\mathrm{mmol} / \mathrm{L}\end{array}$ & $4.81(1.12)$ & $5.36(1.22)$ \\
\hline Triglycerides, mmol/L & $1.46(1.04-2.12)$ & $1.62(1.17-2.28)$ \\
\hline $\mathrm{HDL}-\mathrm{C}, \mathrm{mmol} / \mathrm{L}$ & $1.11(0.26)$ & $1.29(0.30)$ \\
\hline LDL-C, mmol/L & $2.99(0.79)$ & $3.28(0.88)$ \\
\hline Current smoking, \% & 36.7 & 2.4 \\
\hline Hypertension, \% & 78.0 & 79.2 \\
\hline Dyslipidemia, \% & 63.2 & 60.8 \\
\hline Vitamin D intake, \% & 6.5 & 12.4 \\
\hline $\begin{array}{l}\text { Anti-osteoporosis } \\
\text { medication, } \%\end{array}$ & 13.5 & 28.4 \\
\hline
\end{tabular}

The data are summarized as the mean (s.D.) or median (interquartile range) for continuous variables or as a numerical proportion for categorical variables.

25(OH)D, 25-hydroxy vitamin D; CTX, collagen type 1 C-telopeptide; eGFR estimated glomerular filtration rate; FPG, fasting plasma glucose; $\mathrm{HbA} 1 \mathrm{c}$, glycated haemoglobin HDL-C, high-density lipoprotein; LDL-C, low-density lipoprotein; P1NP, procollagen type $1 \mathrm{~N}$-terminal propeptide. associated with $25(\mathrm{OH}) \mathrm{D}$ and positively associated with BLL (all $P<0.01$ ) after adjusting for participant age, current smoking habits, vitamin D intake, BMI, dyslipidemia, hypertension, duration of diabetes and use of anti-osteoporosis medication. Vitamin D deficiency was also associated with higher P1NP, N-MID osteocalcin and $\beta$-CTX levels.

Regarding the metabolic risk factors, in men, FPG, HbA1c, lipid profile and blood pressure were inversely associated with $25(\mathrm{OH}) \mathrm{D}$, while in women, the associations only held for BMI and lipid profile. Interestingly, there was a significant association between BMI and BLL in women but not in men, which was consistent with our previous paper in the general population (10). BLL was also significantly associated with eGFR and triglycerides in both sexes (Fig. 2 and Table 2).

\section{Mediation analysis}

After finding that P1NP, N-MID osteocalcin and $\beta$-CTX levels were associated with both vitamin D and BLL, we further performed a mediation analysis to try to understand whether the bone turnover markers were significant mediators between vitamin D and BLL. Figure 1 illustrates the model for the mediation effect. ' $a$ ' indicates the path from $25(\mathrm{OH}) \mathrm{D}$ (exposure) to mediators, ' $\mathrm{b}$ ' indicates the path from mediators to BLL (outcome), ' $c$ ' indicates the path from 25(OH)D (exposure) to BLL (outcome) and ' $\mathrm{c}$ ' indicates the direct path from $25(\mathrm{OH}) \mathrm{D}$ (exposure) to BLL (outcome) when controlled for mediators (Table 3).

In Table 3, we found very consistent results in both sexes and in bone formation and resorption markers. None of the direct associations between 25(OH)D and BLL were significant in P1NP, N-MID osteocalcin and $\beta$-CTX mediation analysis, but all the indirect or mediated associations were significant. Because these associations were not significant after additional adjustment for P1NP, N-MID osteocalcin and $\beta$-CTX concentrations, P1NP, $\mathrm{N}$-MID osteocalcin and $\beta$-CTX had a complete mediation effect on these associations. To exclude the effect of occupation on the lead exposure, we made a sensitivity analysis in women over 60 and men over 65 , and the results were not materially changed (Supplementary Table 1).

\section{Discussion}

In this study on community-dwelling Chinese adults with type 2 diabetes, we reported that plasma bone turnover markers, including P1NP, N-MID osteocalcin and $\beta$-CTX,

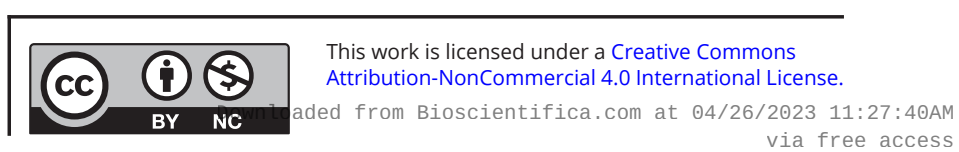




\section{1}

Men

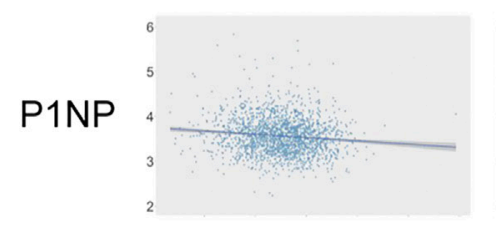

\section{(1)}
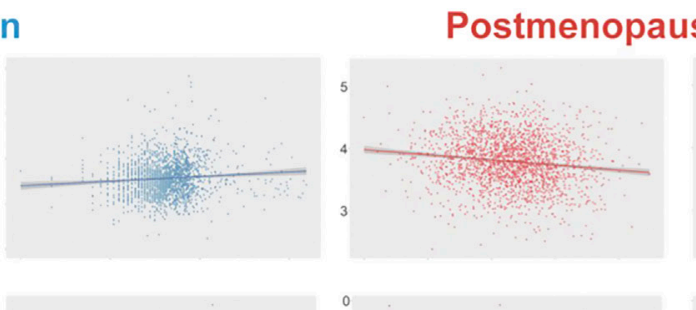

Postmenopausal Women
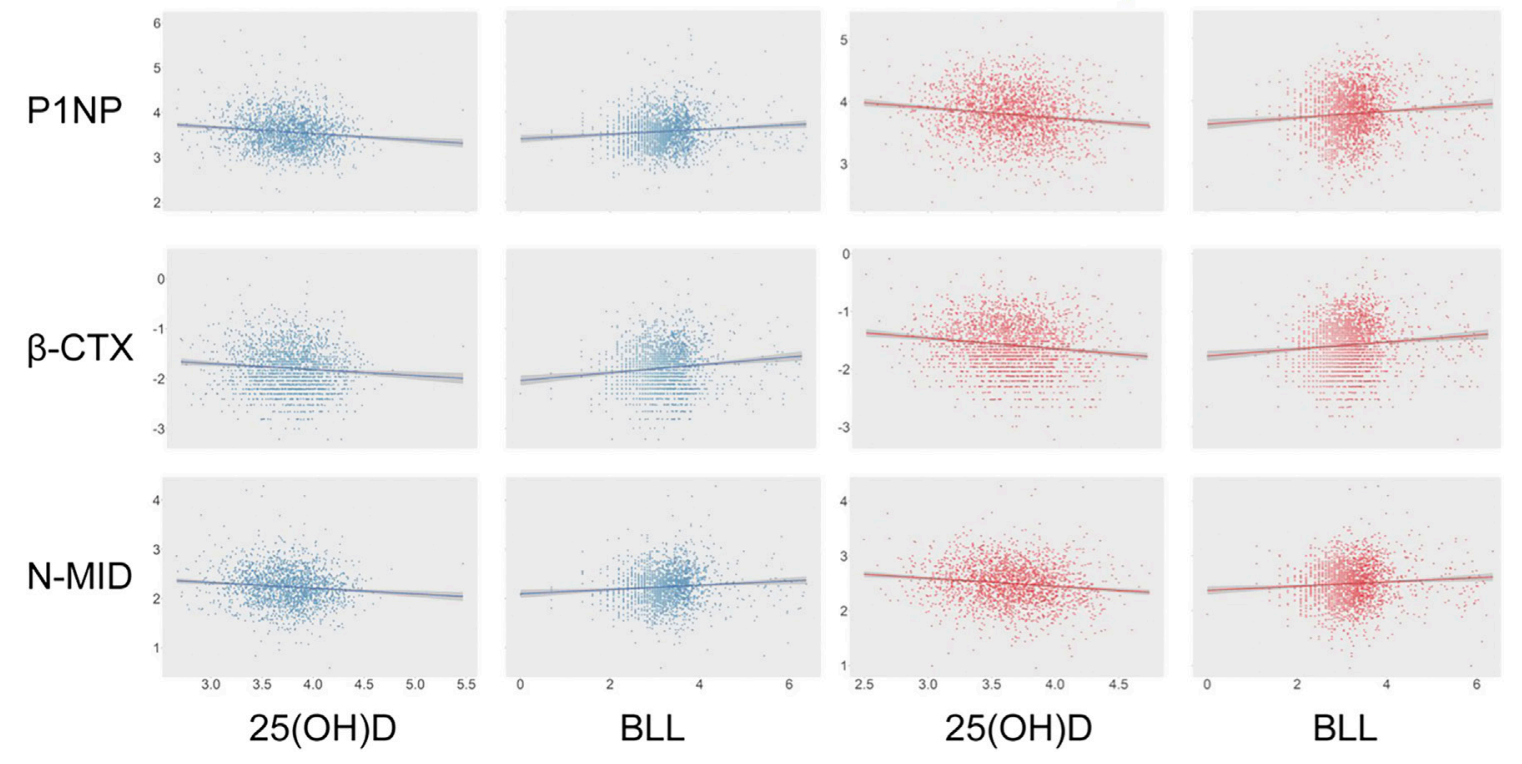

BLL

\section{Figure 2}

Scatter plot among vitamin D, blood lead level and bone turnover markers in men and postmenopausal women. All the lines above showed significant trends (all $P<0.001$ ). 25(OH)D, blood lead level, P1NP, N-MID osteocalcin and $\beta$-CTX were natural logarithm transformed. 25(OH)D, 25-hydroxy vitamin D; $\mathrm{BLL}$, blood lead level; CTX, collagen type $1 \mathrm{C}$-telopeptide; P1NP, procollagen type $1 \mathrm{~N}$-terminal propeptide. The gray around the line represents $95 \% \mathrm{Cl}$.

were positively associated with BLL and inversely associated with $25(\mathrm{OH}) \mathrm{D}$. P1NP, N-MID osteocalcin and $\beta$-CTX completely mediated the relationship between 25(OH)D and BLL. The current study is, to our knowledge, the first to identify the mediating effect of bone turnover markers on the relationship between vitamin $\mathrm{D}$ and blood lead exposure in humans. The mediation effect might indicate an association between exposure to vitamin $\mathrm{D}$ deficiency and a higher bone turnover rate, which may then contribute to greater blood lead exposure (Fig. 3).

The relationship between vitamin $\mathrm{D}$ and BLL has been noted in previous studies that primarily focused on children. Children with high lead exposure displayed a significant negative association between the 1,25-dihydroxyvitamin $\mathrm{D}$ and 25(OH)D concentrations and BLL $(28,29)$. In a Chinese population-based study on 1218 children, after multivariable adjustment, in addition to increasing child age, BLL was the other significant predictor of 25(OH)D deficiency and insufficiency (OR $1.01,95 \%$ CI 1.00, 1.02) (29). Furthermore, another cohort study demonstrated that increasing dietary calcium and vitamin D intake during pregnancy could be associated with lower maternal BLL and lower lead in cord blood (30). Conversely, animal studies have shown that lead exposure in water significantly decreased the $25(\mathrm{OH}) \mathrm{D}$ and affected the expression of vitamin D-metabolizing enzymes in the brain, liver and kidneys (31). Thus, vitamin D and lead exposure may have a bidirectional association, which values further determination. However, interestingly, there is also another opposite viewpoint about vitamin D and lead exposure. Prior studies indicated that vitamin D ingestion not only stimulated the absorption of calcium and phosphate but also toxic metals, including lead and cadmium (32). However, that intervention was largely in animals (32), and there is still a lack of data on how the BLL would change when vitamin D supplementation is given to different age groups of humans.

A significant negative correlation between the $25(\mathrm{OH}) \mathrm{D}$ concentration and bone turnover in older people presenting a high prevalence of vitamin $\mathrm{D}$ deficiency was discovered $(17,33)$. A study based on 1724 postmenopausal women with remarkably low levels of 25(OH)D (mean $33 \mathrm{nmol} / \mathrm{L}$ ) in Peking suggested an inverse association of $25(\mathrm{OH}) \mathrm{D}$ with $\beta$-CTX and P1NP $(\mathrm{r}=-0.073$ and $-0.088, P<0.01$ ) (33). Moreover, a study based on Australian women who did not receive dietary vitamin D demonstrated that with the seasonal change in vitamin $\mathrm{D}$ levels, decreased $25(\mathrm{OH}) \mathrm{D}$ in winter could result in increased bone resorption (34). Additionally, vitamin D supplementation for correcting vitamin D deficiency in patients showed significant effects regarding decreasing bone turnover (35). Interestingly, in people with higher 25(OH)D levels, some randomized controlled trials indicated no significant influence of vitamin $\mathrm{D}$ on bone

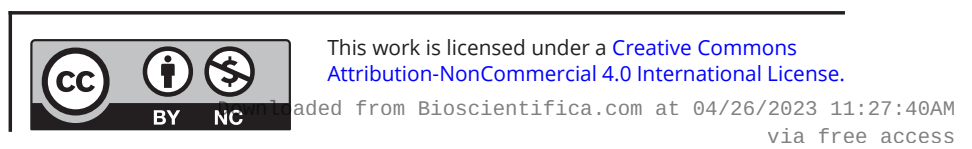



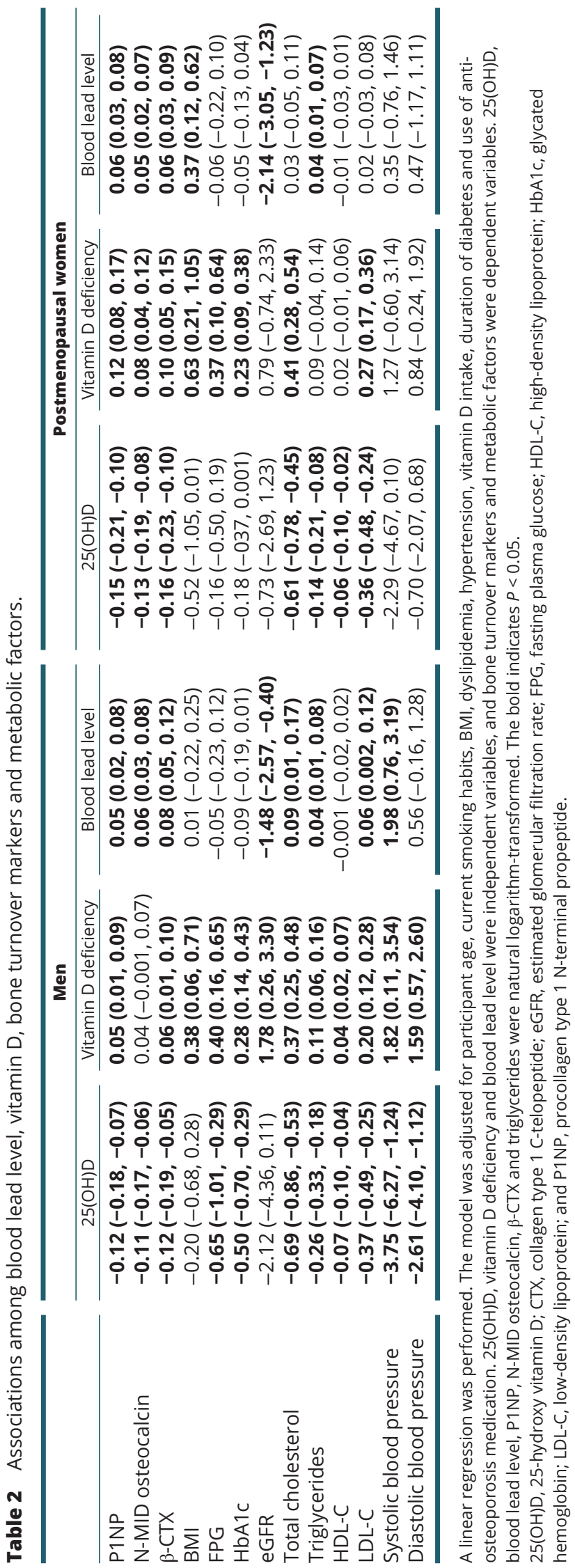

https://ec.bioscientifica.com https://doi.org/10.1530/EC-21-0006 (c) 2021 The authors Published by Bioscientifica Ltd turnover $(36,37)$. Combined with our results, vitamin D may be considered a nutrient with a threshold and influence on bone turnover under conditions of vitamin D insufficiency. The mechanism of the association may be that the parathyroid hormone (PTH) mediates vitamin D and bone turnover. A continuous elevation in serum PTH with decreasing serum $25(\mathrm{OH}) \mathrm{D}$ and no plateau was found (17). PTH may up-regulate the expression of the NF- $\mathrm{kB}$ ligand receptor activator, inhibit osteoprotegerin mRNA expression, and accelerate bone turnover (38). In animal models, $1 \alpha(\mathrm{OH})$ ase knockout mice developed hypocalcemia and osteomalacia. Despite hypocalcemia correction, the osteoblast number, mineral apposition rate, and bone volume were still below those of WT mice. Treating with exogenous $1,25(\mathrm{OH})_{2} \mathrm{D}_{3}$ normalized the osteoblast number in mutant mice (39).

The majority of lead (80-85\%) is deposited in bones under environmental and occupational exposure, and its half-life is rather long (over 10 years) (14). The bone deposition site could be two compartments, the exchangeable compartment at the surface of the bone and the non-exchangeable compartment deeper in the cortical bone. In addition to easily entering the blood, when lead is actively reabsorbed, cortical bone is exchanged to the surface (40). Epidemiological studies have shown that skeletal lead could be an endogenous source of lead exposure when the bone turnover rate is increased (41, 42 ). With the measurement of bone turnover markers, Machida et al. demonstrated that in Japanese women, BLLs were significantly lower in the group with low osteocalcin, showing a strong positive correlation between BLL and bone formation (43). Moreover, another study found that collagen type I N-telopeptide in addition to bone-specific alkaline phosphatase was associated with higher BLL in postmenopausal women, which indicated that the BLL was also associated with bone resorption (15). Consistent with these results, we found that although men had a relatively lower bone turnover rate than postmenopausal women, the inverse association between lower bone turnover and lower BLL still occurred. In summary, active bone turnover, whether in formation or resorption, might cause an increase in the BLL as a result of skeletal lead mobilization into blood.

To understand the possible role that bone metabolism plays in the association between vitamin D and BLL, we conducted a mediation analysis. Our results indicated that the association between vitamin D and blood lead was mediated by bone turnover markers, which acted as a full mediator. Our finding has several important implications. First, because bone is a primary reservoir 
Table 3 Mediation of bone turnover markers on the association between 25(OH)D and blood lead levels.

\begin{tabular}{l} 
Effect \\
a (exposure $\rightarrow$ mediator) \\
b (mediator $\rightarrow$ outcome) \\
c (total effect) \\
$c^{\prime}($ direct effect) \\
ab (mediated effect) \\
a (exposure $\rightarrow$ mediator) \\
b (mediator $\rightarrow$ outcome) \\
$c$ (total effect) \\
$c^{\prime}($ direct effect) \\
ab (mediated effect) \\
\hline
\end{tabular}

\begin{tabular}{|c|c|}
\hline P1NP & \\
\hline$-0.128(-0.186,-0.070)$ & \\
\hline $0.111(0.032,0.191)$ & \\
\hline$-0.022(-0.119,0.075)$ & \\
\hline$-0.008(-0.105,0.090)$ & \\
\hline$-0.014(-0.029,-0.003)$ & \\
\hline$-0.144(-0.200,-0.088)$ & \\
\hline $0.129(0.052,0.206)$ & \\
\hline$-0.078(-0.174,0.018)$ & \\
\hline$-0.060(-0.157,0.036)$ & \\
\hline$-0.019(-0.036,-0.005)$ & \\
\hline
\end{tabular}

\begin{tabular}{c}
\hline -СTX \\
\hline Men \\
$-\mathbf{0 . 1 2 3}(-\mathbf{0 . 1 8 9},-\mathbf{0 . 0 5 7})$ \\
$\mathbf{0 . 1 4 8}(\mathbf{0 . 0 7 8}, \mathbf{0 . 2 1 7})$ \\
$-0.022(-0.119,0.075)$ \\
$-0.004(-0.101,0.094)$ \\
$-\mathbf{0 . 0 1 8}(-\mathbf{0 . 0 3 4},-\mathbf{0 . 0 0 6})$ \\
$-\mathbf{0 . 1 4 9}(-\mathbf{0 . 2 1 0},-\mathbf{0 . 0 8 7})$ \\
$-\mathbf{0 . 1 0 4}(\mathbf{0 . 0 3 3}, \mathbf{0 . 1 7 5})$ \\
$-0.078(-0.174,0.018)$ \\
$-0.063(0.160,0.033)$ \\
$-\mathbf{0 . 0 1 6}(-\mathbf{0 . 0 3 0},-\mathbf{0 . 0 0 5})$
\end{tabular}

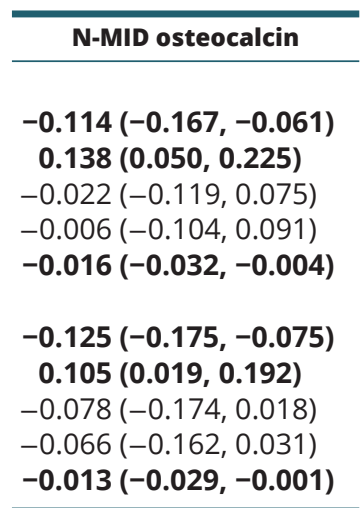

The model was adjusted for current smoking habits, vitamin D intake, BMI, dyslipidemia, hypertension, estimated glomerular filtration rate, duration of diabetes and use of anti-osteoporosis medication. 25(OH)D, blood lead level, P1NP, N-MID osteocalcin and $\beta$-CTX were natural logarithm-transformed. The bold indicates $P<0.05$.

25(OH)D, 25-hydroxy vitamin D; CTX, collagen type 1 C-telopeptide; and P1NP, procollagen type $1 \mathrm{~N}$-terminal propeptide.

of lead in the human body, a higher bone turnover rate may release more lead into the blood. Secondly, the higher bone turnover rate in the elderly may be related to vitamin D deficiency. Taken together, this finding implied that diabetic patients experiencing vitamin D deficiency and a high bone turnover rate may have a greater state of blood lead exposure. The elevated bone turnover rate may serve as an early marker related to blood lead exposure.

This study had some limitations. First, readers should be cautious in interpreting the mediation results because this study is cross-sectional in nature; thus, unmeasured or residual confounding and causal relationships or coincidental phenomena cannot be fully determined. Secondly, Han Chinese and elderly diabetic patients were the study group; thus, the results may not be generalizable to other population groups. Thirdly, a one-time sampling design may result in measurement error.

In conclusion, we reported that the association between vitamin D and BLL was fully mediated by bone turnover markers in type 2 diabetic patients (mediation effect). The mechanism may be due to the direct participation of bone turnover in promoting blood lead exposure. This finding suggested that exposure to vitamin D deficiency might induce a higher bone turnover rate, which then contributed to greater blood lead exposure, regardless of sex. Whether higher vitamin D concentrations or vitamin D supplementation could ameliorate blood lead exposure should be further determined by prospective studies or trials.

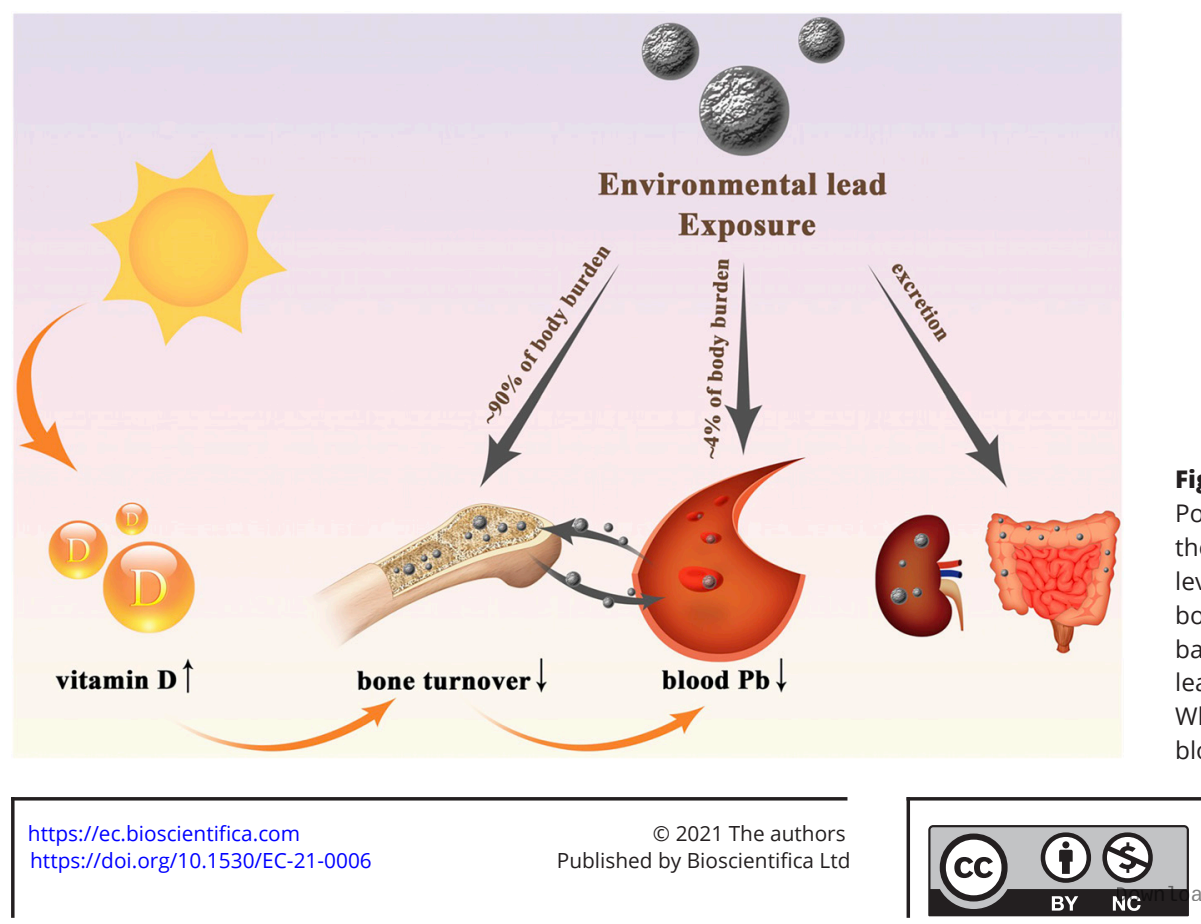

Figure 3

Potential mediation effect of bone metabolism on the association between vitamin $\mathrm{D}$ and blood lead level. About $90 \%$ of body lead is deposited in the bone, and bone and blood lead are in a dynamic balance. Vitamin $D$ deficiency may increase blood lead exposure through active bone turnover. Whether vitamin D supplementation could reduce blood lead level needs further exploration. 


\section{Supplementary materials}

This is linked to the online version of the paper at https://doi.org/10.1530/ EC-21-0006.

\section{Declaration of interest}

All authors have completed the ICMJE uniform disclosure form at www. icmje.org/coi_disclosure.pdf and declare: no support from any organization for the submitted work.

\section{Funding}

This study was supported by National Natural Science Foundation of China (91857117); Science and Technology Commission of Shanghai Municipality (19140902400, 18410722300, 20ZR1432500); the Major Science and Technology Innovation Program of Shanghai Municipal Education Commission (2018YFC1705103); Shanghai Municipal Human Resources and Social Security Bureau (2020074), Clinical Research Plan of SHDC (SHDC2020CR4006). The funders played no role in the design or conduct of the study, collection, management, analysis, or interpretation of data or in the preparation, review, or approval of the article.

\section{Acknowledgement}

The authors thank all team members and participants in the METAL study.

\section{References}

$1 \mathrm{Hu}$ C \& Jia W. Diabetes in China: epidemiology and genetic risk factors and their clinical utility in personalized medication. Diabetes 201867 3-11. (https://doi.org/10.2337/dbi17-0013)

2 Bener A, Obineche E, Gillett M, Pasha MAH \& Bishawi B. Association between blood levels of lead, blood pressure and risk of diabetes and heart disease in workers. International Archives of Occupational and Environmental Health 200174 375-378. (https://doi.org/10.1007/ s004200100231)

3 Kolachi NF, Kazi TG, Afridi HI, Kazi N, Khan S, Kandhro GA, Shah AQ, Baig JA, Wadhwa SK, Shah F, et al. Status of toxic metals in biological samples of diabetic mothers and their neonates. Biological Trace Element Research 2011143 196-212. (https://doi.org/10.1007/ s12011-010-8879-7)

4 Forouhi NG, Ye Z, Rickard AP, Khaw KT, Luben R, Langenberg C \& Wareham NJ. Circulating 25-hydroxyvitamin D concentration and the risk of type 2 diabetes: results from the European Prospective Investigation into Cancer (EPIC)-Norfolk cohort and updated metaanalysis of prospective studies. Diabetologia 201255 2173-2182. (https://doi.org/10.1007/s00125-012-2544-y)

5 Bener A, Al-Hamaq AOAA, Kurtulus EM, Abdullatef WK \& Zirie M. The role of vitamin D, obesity and physical exercise in regulation of glycemia in type 2 diabetes mellitus patients. Diabetes and Metabolic Syndrome 201610 198-204. (https://doi.org/10.1016/j. dsx.2016.06.007)

6 Needleman H. Lead poisoning. Annual Review of Medicine 200455 209-222. (https://doi.org/10.1146/annurev.med.55.091902.103653)

7 Wang N, Lu M, Chen C, Xia F, Han B, Li Q, Cheng J, Chen Y, Zhu C, Jensen $\mathrm{MD}$, et al. Adiposity genetic risk score modifies the association between blood lead level and body mass index. Journal of Clinical Endocrinology and Metabolism 2018103 4005-4013. (https://doi. org/10.1210/jc.2018-00472)

8 Nie X, Chen Y, Chen Y, Chen C, Han B, Li Q, Zhu C, Xia F, Zhai $\mathrm{H}$, Wang $\mathrm{N}$, et al. Lead and cadmium exposure, higher thyroid antibodies and thyroid dysfunction in Chinese women.
Environmental Pollution 2017230 320-328. (https://doi.org/10.1016/j. envpol.2017.06.052)

9 Li MM, Cao J, Xu J, Cai SZ, Shen XM \& Yan CH. The national trend of blood lead levels among Chinese children aged 0-18 years old, 1990-2012. Environment International 201471 109-117. (https://doi. org/10.1016/j.envint.2014.06.005)

10 Wang N, Chen C, Nie X, Han B, Li Q, Chen Y, Zhu C, Chen Y, Xia F, Cang Z, et al. Blood lead level and its association with body mass index and obesity in China - Results from SPECT-China study. Scientific Reports 20155 18299. (https://doi.org/10.1038/ srep18299)

11 Ding C, Pan Y, Zhang A, Wu B, Huang H, Zhu C, Liu D, Zhu B, $\mathrm{Xu} \mathrm{G}$, Shao $\mathrm{H}$, et al. Study of distribution and influencing factors of lead and cadmium in whole blood and urine among population in 8 provinces in China. Zhonghua Yu Fang Yi Xue Za Zhi 2014 48 91-96. (https://doi.org/10.1111/jedm.1205010.3760/cma.j.i ssn.0253-9624.2014.02.004)

12 Obeng-Gyasi E. Sources of lead exposure in various countries. Reviews on Environmental Health 201934 25-34. (https://doi.org/10.1515/ reveh-2018-0037)

13 Barry PS. A comparison of concentrations of lead in human tissues. British Journal of Industrial Medicine 197532 119-139. (https://doi. org/10.1136/oem.32.2.119)

14 Bergdahl IA, Strömberg U, Gerhardsson L, Schütz A, Chettle DR \& Skerfving S. Lead concentrations in tibial and calcaneal bone in relation to the history of lead exposure. Scandinavian Journal of Work, Environment and Health 19981 38-45. (https://doi.org/10.5271/ sjweh.276)

15 Jackson LW, Cromer BA \& Panneerselvamm A. Association between bone turnover, micronutrient intake, and blood lead levels in preand postmenopausal women, NHANES 1999-2002. Environmental Health Perspectives 2010118 1590-1596. (https://doi.org/10.1289/ ehp.1002158)

16 Lips P. Vitamin D deficiency and secondary hyperparathyroidism in the elderly: consequences for bone loss and fractures and therapeutic implications. Endocrine Reviews 200122 477-501. (https://doi. org/10.1210/edrv.22.4.0437)

17 Kuchuk NO, Pluijm SM, van Schoor NM, Looman CW, Smit JH \& Lips P. Relationships of serum 25-hydroxyvitamin D to bone mineral density and serum parathyroid hormone and markers of bone turnover in older persons. Journal of Clinical Endocrinology and Metabolism 2009 94 1244-1250. (https://doi.org/10.1210/jc.2008-1832)

18 Wan H, Wang Y, Zhang K, Chen Y, Fang S, Zhang W, Wang C, Li Q, Xia F, Wang N, et al. Associations between vitamin D and microvascular complications in middle-aged and elderly diabetic patients. Endocrine Practice 201925 809-816. (https://doi. org/10.4158/EP-2019-0015)

19 Carlson RV, Boyd KM \& Webb DJ. The revision of the Declaration of Helsinki: past, present and future. British Journal of Clinical Pharmacology 200457 695-713. (https://doi.org/10.1111/j.13652125.2004.02103.x)

20 Wang N, Chen Y, Ning Z, Li Q, Han B, Zhu C, Chen Y, Xia F, Jiang B, Wang B, et al. Exposure to famine in early life and nonalcoholic fatty liver disease in adulthood. Journal of Clinical Endocrinology and Metabolism 2016101 2218-2225. (https://doi.org/10.1210/jc.20161076)

21 Wang N, Wang X, Li Q, Han B, Chen Y, Zhu C, Chen Y, Lin D, Wang $\mathrm{B}$, Jensen $\mathrm{MD}$, et al. The famine exposure in early life and metabolic syndrome in adulthood. Clinical Nutrition 201736 253-259. (https://doi.org/10.1016/j.clnu.2015.11.010)

22 Xu Y, Wang L, He J, Bi Y, Li M, Wang T, Wang L, Jiang Y, Dai M, Lu J, et al. Prevalence and control of diabetes in Chinese adults. JAMA 2013310 948-959. (https://doi.org/10.1001/jama.2013.168118)

23 Pearce SH \& Cheetham TD. Diagnosis and management of vitamin D deficiency. BMJ 2010340 b5664. (https://doi.org/10.1136/bmj. b5664)

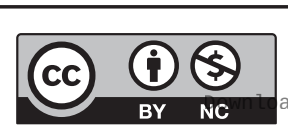

This work is licensed under a Creative Commons Attribution-NonCommercial 4.0 International License. ded from Bioscientifica.com at 04/26/2023 11:27:40AM 
24 Liu LS. 2018 Chinese guidelines for the management of hypertension. Chinese Journal of Cardiovascular Medicine 201924 24-56. (https://doi.org/10.3760/cma.j.issn.0253-3758.2011.07.002)

25 Grundy SM, Cleeman JI, Merz CN, Brewer Jr HB, Clark LT, Hunninghake DB, Pasternak RC, Smith Jr SC, Stone NJ, National Heart, Lung, and Blood Institute, et al. Implications of recent clinical trials for the National Cholesterol Education Program Adult Treatment Panel III guidelines. Circulation 2004110 227-239. (https://doi.org/10.1161/01.CIR.0000133317.49796.0E)

26 Stevens LA, Claybon MA, Schmid CH, Chen J, Horio M, Imai E, Nelson RG, Van Deventer M, Wang HY, Zuo L, et al. Evaluation of the chronic kidney disease epidemiology collaboration equation for estimating the glomerular filtration rate in multiple ethnicities. Kidney International 201179 555-562. (https://doi.org/10.1038/ ki.2010.462)

27 Hayes AF. Introduction to mediation, moderation, and conditional process analysis: a regression-based approach, 2013. New York, NY, USA: The Guilford Press.

28 Rosen JF, Chesney RW, Hamstra A, DeLuca HF \& Mahaffey KR. Reduction in 1,25-dihydroxyvitamin D in children with increased lead absorption. New England Journal of Medicine $1980 \mathbf{3 0 2}$ 1128-1131. (https://doi.org/10.1056/NEJM198005153022006)

29 Chang L, Liu X, Shi H, Dai W, Wang H \& Jiang Y. Association of 25-hydroxyvitamin $\mathrm{D}$ with $\mathrm{Hb}$ and lead in children: a Chinese population-based study. Public Health Nutrition 201417 827-832. (https://doi.org/10.1017/S1368980013001675)

30 Arbuckle TE, Liang CL, Morisset AS, Fisher M, Weiler H, Cirtiu CM, Legrand M, Davis K, Ettinger AS, Fraser WD, et al. Maternal and fetal exposure to cadmium, lead, manganese and mercury: the MIREC study. Chemosphere 2016163 270-282. (https://doi.org/10.1016/j. chemosphere.2016.08.023)

31 Rahman A, Al-Awadi AA \& Khan KM. Lead affects vitamin D metabolism in rats. Nutrients 201810 264. (https://doi.org/10.3390/ nu10030264)

32 Moon J. The role of vitamin D in toxic metal absorption: a review. Journal of the American College of Nutrition 199413 559-564. (https:// doi.org/10.1080/07315724.1994.10718447)

33 Zhao J, Xia W, Nie M, Zheng X, Wang Q, Wang X, Wang W, Ning Z, Huang W, Jiang Y, et al. The levels of bone turnover markers in Chinese postmenopausal women: Peking Vertebral Fracture Study. Menopause 201118 1237-1243. (https://doi.org/10.1097/ gme.0b013e31821d7ff7)

34 Pasco JA, Henry MJ, Kotowicz MA, Sanders KM, Seeman E, Pasco JR, Schneider HG \& Nicholson GC. Seasonal periodicity of serum vitamin D and parathyroid hormone, bone resorption, and fractures: the Geelong osteoporosis study. Journal of Bone and Mineral Research 200419 752-758. (https://doi.org/10.1359/JBMR.040125)

35 Tanzy ME \& Camacho PM. Effect of vitamin D therapy on bone turnover markers in postmenopausal women with osteoporosis and osteopenia. Endocrine Practice 201117 873-879. (https://doi. org/10.4158/EP10339.OR)

36 Schwetz V, Trummer C, Pandis M, Grübler MR, Verheyen N, Gaksch M, Zittermann A, März W, Aberer F, Lang A, et al. Effects of vitamin D supplementation on bone turnover markers: a randomized controlled trial. Nutrients 20179 432. (https://doi.org/10.3390/ nu9050432)

37 Lerchbaum E, Trummer C, Theiler-Schwetz V, Kollmann M, Wölfler M, Pilz S \& Obermayer-Pietsch B. Effects of vitamin D supplementation on bone turnover and bone mineral density in healthy men: a post-hoc analysis of a randomized controlled trial. Nutrients 201911 731. (https://doi.org/10.3390/nu11040731)

38 Lee SK \& Lorenzo JA. Parathyroid hormone stimulates TRANCE and inhibits osteoprotegerin messenger ribonucleic acid expression in murine bone marrow cultures: correlation with osteoclast-like cell formation. Endocrinology 1999140 3552-3561. (https://doi. org/10.1210/endo.140.8.6887)

39 Panda DK, Miao D, Bolivar I, Li J, Huo R, Hendy GN \& Goltzman D. Inactivation of the 25-hydroxyvitamin D 1alpha-hydroxylase and vitamin D receptor demonstrates independent and interdependent effects of calcium and vitamin D on skeletal and mineral homeostasis. Journal of Biological Chemistry 2004279 16754-16766. (https://doi.org/10.1074/jbc.M310271200)

40 Mitra P, Sharma S, Purohit P \& Sharma P. Clinical and molecular aspects of lead toxicity: an update. Critical Reviews in Clinical Laboratory Sciences 201754 506-528. (https://doi.org/10.1080/10408 363.2017.1408562)

41 Morrow L, Needleman HL, McFarland C, Metheny K \& Tobin M. Past occupational exposure to lead: association between current blood lead and bone lead. Archives of Environmental and Occupational Health 200762 183-186. (https://doi.org/10.3200/AEOH.62.4.183-186)

42 Manton WI, Angle CR, Stanek KL, Kuntzelman D, Reese YR \& Kuehnemann TJ. Release of lead from bone in pregnancy and lactation. Environmental Research 200392 139-151. (https://doi. org/10.1016/s0013-9351(03)00020-3)

43 Machida M, Sun SJ, Oguma E \& Kayama F. High bone matrix turnover predicts blood levels of lead among perimenopausal women. Environmental Research 2009109 880-886. (https://doi. org/10.1016/j.envres.2009.06.005)

Received in final form 19 February 2021

Accepted 3 March 2021

Accepted Manuscript published online 5 March 2021 https://ec.bioscientifica.com https://doi.org/10.1530/EC-21-0006 (c) 2021 The authors Published by Bioscientifica Ltd

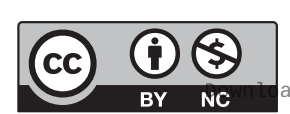

This work is licensed under a Creative Commons Attribution-NonCommercial 4.0 International License. ded from Bioscientifica.com at 04/26/2023 11:27:40AM 